Dr. Angus Smith, F.R.S., and Mr. Robert Rawlinson, C.B., have been appointed by the Local Government Board inspectors for the purpose of granting certificates under the Rivers Pollution Prevention Act, 1876.

TrphoID Fever has broken out among the crew of the guardship Valiant in Foynes Harbour. An application has been made to the governor of a local hospital to accommodate fifteen cases.

Frest cases of small-pox continue to be reported in Liverpool. Last week fifteen deaths from the disease were recorded.

\section{THE SMALL-POX EPIDEMIC.}

THe fatality from small-pox in London has, with slight fluctuations, increased steadily since the beginning of October, and the 75 deaths from the disease registered during the seven days ending 16 th considerably exceeded any weekly number since the decline of the epidemic in 1870.1-2. These 75 deaths showed an increase of 25 upon those returned in the preceding week, most of which increase occurred in South London, to which 31 of the 75 fatal cases belonged. After distributing the hospital cases, the Registrar-General's last weekly returns showed that 11 of the deceased small-pox patients had resided in Hackney, 8 in Lambeth, 8 in Camberwell, 5 in Islington, 4 in Bow, 4 in St. $P_{\text {ancras, }} 4$ in Wandsworth, and 4 in St. Saviour's, Southwark. The marked increase in the recorded fatal cases was not, however, the only unfavourable feature of the last return. The number of small-pox patients under treatment in the Metropolitan Asylum Small-pox Hospitals at Homerton, Stockwell, and Hampstead, which in the seven preceding weeks bad steadily increased from 185 to 586 , further rose to 696 during the week ending the 16th. Accommodation for this additional number of patients had in great measure been provided by the transferrence of the fever patients from the Homerton Fever Hospital to the similar institution at Stockwell. Bearing in mind that during the first half of this year only 33 deaths from small-pox were registered in London, the increase in the numbers has been far more rapid than it was at the commencement of the last epidemic; during the three months ending September 110 fatal cases were recorded, and in the eleven weeks ending $16 \mathrm{th}, 420$ further cases. It is scarcely possible to believe that the present epidemic can, in a more generally vaccinated population, assume the same proportions as did the last; butin the face of the recent ominous increase in the number of cases and of deaths, it is well to remember the fact that in 1871 no less than 7876 small-pox deatbs were registered in London, and at the crisis of the epidemic, in the early part of May of that year, 288 occurred in one week. Notwithstanding the increase of hospital accommodation the proportion of fatal cases in private dwelling-houses continues between 40 and 50 per cent. It is evident, therefore, that the Metropolitan Asylums Board is bound rapidly to increase their number of beds for small-pox patients, and it is to be hoped that they will meet with cordial support both from the Government and the public in their thankless task. The assistance of the public may be rendered in two important directionsby practically recognising the importance of revaccination, and by not offering litigious local opposition to every site proposed for temporary hospital accommodation. Local sanitary authorities can render most valuable assistance by adoptivg all possible means for daily information to their medical officers of health of new cases of small-pox, in which effort the co-operation of all medical practitioners can doubtless be counted upon.

Around London the most noticeable feature with reference to the prevalence of small-pox is the occurrence of four fatal cases in the infectious wards of the Croydon Workhouse during the week ending the 16 th inst. Two were also recorded in the district of West Ham

Much exaggeration appears to have prevailed with regard to reported outbreaks of small-pox in various parts of the country, but judging from a few facts published by the Registrar-General, the ontbreak at Bromley is the only one that has assumed serious proportions. In Bromley seventeen deaths occurred between the end of September and the 16th inst.; three were registered in $\mathrm{S}$ wansea, two in Kendal, and one each in Blackburn and Haslingden. No death in Chatham was registered prinr to the 16 th inst. Loudon, Liverpool, Manchester, Silford, and Bromley, appear to be the only towns in which the disease has assumed an epidemic character, and it may yet be hoped that the epidemic may not become general, as it did in 1871-2.

\section{Correspondence.}

"Audi alteram partem."

\section{DIAGNOSIS OF INTRA-THORACIC TUMOURS.} To the Editor of The Lancet.

Sir,-In The LaNCet of Nov. 18th, 1876, are published some "Clinical Remarks on a Case of Mediastinal Cancer with Aphonia from Laryngeal Paralysis," by Dr. Burney Yeo. In his comments on the case he lays considerable stress on the use of the laryngoscope in the diagnosis of these tumours, and, as a very similar instance was lately under my own care in St. George's Hospital, I venture to send you a brief extract from the notes in case you should think them worthy of publication. At the same time, I do not know that I should have troubled you with a com. munication on this subject had it not been for the concluding paragraph of Dr. Yeo's lecture, wherein he says: "The chief point of interest in this case, and that to which I wish to call attention in placing it on record, is the aid which was afforded us in our diagnosis by the use of the laryngoscope, whereby we were enabled at once to discover that the loss of voice was not caused by intrinsic disease of the larynx itself, but by disease within the thorax interfering with the innervation of the largngeal muscles." This fact has, I think, been long recognised by the profession, and no physician who had a case in which any altertion in the force or character of the voice existed would, I imagine, fail to have recourse to the laryngoscope in order that any doubt which might exist as to intrinsic or extrinsic disease of the larynx might at once be set at rest. My own case so closely resembles Dr. Yeo's that it seems to be a fitting supplement to his lecture.

Charlotte $R-$, a married woman aged thirty-seven, was transferred to my care by Dr. Cavafy on October 20 th, 1875. Her history was briefly as follows. She had enjoyed good health until June, 1875, when she was attacked with a bad cough and spitting, which symptoms subsided in the course of a week, but from that time she suffered from constant pain in the upper part of the left chest, both in front and behind. She had for a short period before her admission into St. George's Hospital wasted considerably-i. e., she had lost in six weeks three pounds in weight.

On her admission she was decidedly emaciated; had slight sore-throat, but no cough or expectoration; complained of pain over the upper half of the left chest, anteriorly and posteriorly; her voice was reduced to a whisper; her tongue was clean, though she suffered from obstinate constipation.

On Oct. 22nd I examined her with the laryngoscope, and found total paralysis of the left vocal cord, but no other abnormal appearance in the largux. The left chest was wanting in movement on inspiration, and was markedly dull on percussion in front over the upper part of the lung. Similar dulness existed behind; while over the scapular region percussion resonance was, if anything, greater than natural. The bases of both lungs were dull on percussion, but on the right side breathing was distinctly audible; while over the left lung generally respiration was extremely feeble, and at the upper part quite inaudible. No tubular breathing could be detected on the right side, nor were there in the thorax any moist or dry sonnds. Vocal fremitus was entirely absent on the left side. The heart's apex beat about one inch to the left of the sternum, and not below its 
normal position; the base of the heart extended to about half an inch to the right of the sternum. The sounds were clear and natural.

Oct. 29th.-Sonorous rhonchi were beard over the right lung in front; and on the left side both in front and behiud; the bases were a trifle more resonant, and more air seemed to enter the left base than at the previous examination; otherwise the left chest remained in statu quo. It appeared, on inspection of the two sides of the thorax, that the left was the smaller; measurement, however, proved that no difference existed. I'he diagnosis was that the patient was the subject of an intra-thoracic malignant tumour, which, by pressure on the left recurrent nerve, had caused paralysis of the vocal cord. The patient rapidly lost flesh, and on November 3rd experienced some difficulty in swallowing ; the food appeared " to stick" at the sternal notch, and was immediately vomited. She died on November 4 th.

At the examination of the body, twenty-four hours after death, bloody fluid was found in both pleural cavities, but in no great amount, and less in quantity on the left side. A large, soft, white growth lay in the mediastinum, immediately behind the sternum, which bad involved the right lung to the depth of about one inch, while the left was generally infiltrated; the root of this lung was completely surrounded by the tumour, and the left recurrent nerve was so disorganised, as it passed through the mass, that its dissection was rendered impossible. The heart was natural. The laryngeal muscles on the left side were about half the bulk of those on the night, and microscopic examination whowed them to be so altered that almost all traces of normal voluntary muscular tissue had disappearedstructureless granular bands, merely, representing the original muscular fibres. To the naked eye the new growth was white, soft, and for the most part brain-like in character; microscopically examined, it prove to be an alveolar sarcoma.

In such cases the laryngoscope, as has been demonstrated by various observers, assists the diagnosis, not only in showing the absence of laryngeal disease, but also, when such unilateral paralysis exists, in guiding the practitioner in his search for the original disease to deeper parts within the cavity of the thorax where pressure on or other inter. ference with the motor nerve to the part may exist. In this way previously unsuspected aneurisms have been discovered. The unilateral paralysis of the vocal cord, as shown by the laryngoscope, has led to an examination of the chest, where the real seat of the disease existed.

It does not, however, always happen that the laryngoscope thus enables us to form a certain diagnosis, and of this a case which died under my care a few days ago at the Morley Convalescent Hospital at Wimbledon affords a good example. The patient was a woman aged forty, who had spent the last eleven years in India, where she had suffered from dysentery. She was admitted into St. George's, under Dr. Cavafy, for dyspnœa, cougb, and pain in the right side of the chest, and the note made at the time of her admission (June 2nd, 1876) was as follows: "There appears to be some laryngeal stridor, and the cough is slightly laryngeal in character; musical râles all over the chest, inspiration prolonged under the left clavicle, with some dulness on percussion." The apex beat of the heart was scarcely perceptible; there was a soft systolic bruit audible over the aortic valves; no abnormal dulness could be detected on percussion, save that already mentioned as existing behind the left clavicle. Laryngoscopic examination showed complete paralysis of the left vocal cord, which maintained a permanent position about midway between perfect adduction and abduction. During her residence in St. George's, and subsequently at Wimbledon, she was liable to attacks of dyspnoea on slight exertion, and eventually the breatbing at the left apex became tubular, while the vocal fremitus remained about normal. The voice was so husky that vocal resonance was inappreciable in any part of the chest. On August 12th a gumma appeared on the right leg, which ulcerated, but eventually healed under iodide of potassium. The laryngeal stridor, however, steadily increased, and she became liable to spasmodic attacks of dyspnca on awaking in the morning. On Nov. 3rd she had a severe attack of dyspnoea; on Nov. 4th passed a very restless night, owing to difficulty of breathing. Next day bronchitic râles were audible over the whole chest, and copious expectoration of purulent matter commenced. On
Nov. 6 th the percussion was dull, and respiration diminished over the left side, and she had a severe attack of dyspncen, which lasted about two hours, and in the course of the day a similar attack. These symptoms became so urgent that a thorough examination (according to the report of $\mathrm{Mr}$. $\mathrm{R}$. P. Collyns (the resident medical officer at the convalescent hospital) was impossible. On November 10 tb sbe was unch worse, and the copious expectoration ceased. She died next day at noon. At the post-mortem examination pleuro-pneumonia was found affecting both lungs, and in addition acute inflammation of the bronchial tubes. There was an aortic aneurismal sac of the size of an orange communicating with the aorta by an orifice an inch and a balf in diameter. It arose behind the innominate and left subclavian and carotid arteries. The left recurrent nerve was passed over the most projecting portion of thesac, which had compressed the left bronchus considerably. The tissue of the nerve was so altered that nothing but the neurilemma was left.

The diagnosis in this case was that of aortic aneurism, and this opinion was based chiefly on these two facts-viz., the paralysis of the left vocal cord, and on the systolic murmur heard over the base of the heart. Paralysis of the vocal cord demonstrated clearly that there was some tumour which, by its pressure, had interfered with the innervation of the laryngeal muscles on the left side, and altbough the aortic murmur indicated the probability of aneurism, all all other diagnostic signs of that disease were wanting. I an, Sir, yours faithfully,

Thos. Whipham, M.B., F.R.C.P. Green-street, Nov, 25th, 1876.

Assistant-Physician to St. George's Hospital.

\section{MEDICAL WOMEN.}

To the Editor of THE LANCET.

Sin,-In your impression of the 9th ult., under the head of "Annotations," I find the following paragraph :-

"The King and Queen's College of Physicians in Ireland, on the 1st instant, in accordance with their resolution a month ago in favour of Miss Peachy, decided to admit Miss (or Mrs.) Dunbar, M.D. of Zurich, to the examinations for the licence of the College. This step was resisted strongly and unanimously by the obstetrical (sic) members of the College, but without effect."

The person who supplied you with this information should have been more exact. As the last sentence stands, one would suppose that the obstetric Fellows of the College had made an organised resistance against the admission of ladies to the licence of the College. Such was not the case. Your informant would have been more accurate had he said the step was " resisted," \&c., by the obstetric members of the College who were present at the meeting.

There are eight Fellows who practise obstetric medicine, and three only of these were present. The meeting consisted of twenty 'Fellows, and but sixteen of these voted. The members were equal-eight to eight-and the President gave his casting vote, very properly, in favour of the lady. I was prevented from attending, having had other duties to perform in connexion with my chair. Had I been present I should have strenuously supported the motion for the admission of Miss Dunbar. By inserting this in your next impression you will much oblige, Sir,

Your obedient servant,

Dublin, Dec. 16th, 1876.

EDwd. B. Stnclatr, King's Professor of Midwifery.

\section{THE GENERAL MEDICAL COUNCIL AND THE EAST LONDON MEDICAL DEFENCE ASSOCIATION.}

To the Editor of THE LANCET.

Sir,-From 6th October, 1875, to 12th July, 1876, we were frequently promised by the Medical Council that the whole or part of any penalties we might recover under the Medical Act should be handed over to us towards defraying the expenses of any prosecutions we instituted.

We charge the Medical Council with having made these promises, whilst at the same time they knew that the penalties were claimed by the Receiver of Police-that he had, in fact, before claimed them, and detained them; and that, in 